The Canadian Journal of Critical Nursing Discourse

See it. Speak it. Write it. Change it.

\title{
What is Mental Health Nursing Anyway? Advantages and Issues of Utilizing Duoethnography to Understand Mental Health Nursing.
}

\author{
Michelle C. Danda, RN, PhD (c) \\ University of Alberta, School of Nursing \\ Cite as: Danda, M. (2020). What is Mental Health Nursing Anyway? Advantages and Issues of Utilizing \\ Duoethnography to Understand Mental Health Nursing. Witness: The Canadian Journal of Critical Nursing \\ Discourse, Vol 2(2), pp 20-28. https://doi.org/10.25071/2291-5796.71
}

\begin{abstract}
In recent decades scholars have begun to question the value of mental health nursing. The term has lost both conceptual and explanatory power in the modern globalized world in which multidisciplinary teams now carry out many functions once unique to the specialization, yet its distinction persists. The purpose of this paper is to explore an emerging research methodology, duoethnography, as an avenue to revive mental health nursing by subverting the dominant post-positivist, scientifically driven, medically framed, evidence-based practice perspective, and to gain greater understanding of the nuances of mental health nursing practice. Duoethnography offers promise in challenging nursing research norms embedded in an empirically based medical model; however, the newness of the method poses potential methodological issues. Duoethnography is a methodology well-suited to explore the question of whether mental health nursing is an outmoded tradition too deeply entrenched in the institutional past, or an emerging profession leading mental health care.
\end{abstract}

Key words: Duoethnography, nursing research, qualitative methods, mental health nursing, psychiatric nursing

Mental health nursing exists on a practical level. Mental health nurses are seen practicing on hospital and community-based psychiatric and mental health inpatient units, and in a wide range of community-based mental health programs. Surely, the mental health nurse is a distinct specialty with unique philosophical underpinnings and practice perspectives that cannot be fulfilled by other nursing specialities. However, Lakeman and Molloy (2018) suggested mental health nursing is a "zombie category," meaning the concept has lost both conceptual and explanatory power in the modern globalized world. Yet its use persists in theory and practice. Australia presents a prime conceptual example of the decline of mental health nursing. Their shift to a generalist nursing model coincided with a steady decline in mental health nursing practice (Lakeman \& Molloy, 2018). Post-registration education in mental health has been described as having "overwhelmingly failed" (Hurley \& Ramsay, 2008, p. 17). There is an apparent mismatch between health organization policies and nursing practice competencies that require increased knowledge and scope of practice, while simultaneously allocating less resources to specialized education and training (Hurley \& Ramsay, 2008). Further, mental health nursing is struggling with clearly defining its professional identity (Lakeman \& Molloy, 2018) and closing 
gaps between actual practice and theoretical conceptions of best-practice (Barker \& Buchanan-Barker, 2011).

Identity formation in mental health nursing is historically rooted in the language of medicine, notably psychiatry, which has deeply influenced the formation of the mental health nurse profession. Transitions of mental health care over time have shaped the identity formation of psychiatric nurses as a distinct speciality necessitating a clear understanding of what mental health nursing is, independently of psychiatry. Mental health nursing theorists have identified the importance of mental health nurses being able to clearly articulate what it is they do, beyond philosophical aspirations. Hurley, Mears and Ramsay (2009) posed a discussion of mental health nursing identity over a decade ago. The context was framed with respect to mental health nursing in the United Kingdom. According to them, professional identity is, "self-evidently bounded and consistent" (p. 54). The socially constructed nature of identity is contingent, contextual and dynamic, meaning mental health nursing is influenced by the identified core values of the profession, most prominently the central value of therapeutic relationship (Hurley et al., 2009).

Duoethnography, a method created by Sawyer and Norris (2015), is a novel approach that allows two or more individuals to explore the meaning they make of common experiences of phenomenon. Application of this method exposes one's history as a collection of learning experiences, allowing for critical examination of how the beliefs that influence their actions were acquired, and the meanings they give to them (Norris et al., 2012). The exploration of the similarities and differences focuses on critical juxtaposition of researchers' narrative experience of a phenomenon, which can be utilized to address the existing conflict and tension in mental health nursing.

The purpose of this paper is to provide an exploration of duoethnography as a potential methodology to revive mental health nursing, by subverting the dominant post-positivist, scientifically driven, evidence-based practice perspective, and to gain greater understandings of mental health nursing practice. The journey that duoethnographic mental health nurse researchers embark on allows an alternative means of understanding conceptualization of mental health nursing, identity formation, and how this is uniquely enacted in the mental healthcare. This novel application within nursing offers promise in challenging research norms that prioritize empirical methods; however, the newness of the method poses potential methodological issues that must be considered and navigated. Issues that may arise from using duoethnography in mental health nursing research may result from the application of an unconventional method in an area of nursing that is facing a professional identity crisis. Also at issue is the lack of firmly established rules and structure, coupled with the risk of storytelling becoming a project of the researcher's selfindulgence, which may limit the intended goal of personal and professional growth. However, duoethnography is well suited to explore whether mental health nursing is an outmoded tradition too deeply entrenched in the institutional past, or ready to emerge as a profession to lead in mental health care (Hurley \& Ramsay, 2008). The exploration begins by situating myself within the discussion, followed by a rationale for using duoethnography to connect mental health research to mental health nursing practice, while highlighting the strengths. I will then explore potential issues and strategies to address these issues.

\section{Contextualizing my Experience}

Duoethnography is most frequently done with two or more researchers. However, for the purpose of demonstrating the process, I will use a technique similar to that used by Sameshima (2013), in which she presented a single-person example by engaging in the process with herself, using the duo-identities of mother and researcher. In the spirit of duoethnography, I will situate myself within my process as a means of establishing reflexivity and selfaccountability. My own journey into mental health nursing began when I made the decision to apply for nursing school in 2006. My decision came after completing a Bachelor of Arts 
degrees in Sociology and Psychology at the University of Calgary in 2003. I worked as a youth care worker and behavioural therapist before making the decision to apply to nursing. I was not sure that I would practice as a nurse until I entered my mental health nursing rotation. I valued the connection and time spent with patients, especially those most often marginalized and stigmatized. I graduated from the Accelerated Track Bachelor of Nursing Program at the University of Calgary in 2008. Throughout my career, I have worked in various mental health and substance use programs in Lower Mainland, British Columbia and in Calgary, Alberta.

I completed a Master of Nursing in 2012 and a Master of Psychiatric Nursing in 2018. I began my Nursing Doctorate program in 2018. I have maintained both direct care nursing practice and clinical teaching practice while completing my graduate degrees. After undertaking my $\mathrm{PhD}$ program, I began to increasingly question the influence and value of evidence-based practice and the mental health research that guides mental health nursing practice. My questioning brought me to also question the underlying value and practices of mental health nursing.

\section{Connecting Research Method to Practice: Making a Case for Duoethnography}

Nursing is thought to be both an art and a science (Mitchell \& Cody, 2002; Rose \& Parker, 1994). Yet the artistic side of nursing is eroding amidst a neoliberal university landscape where legitimacy is sought by increased scientifically-based, biomedically-driven forms of knowledge (Grant \& Radcliffe, 2015; Jenkins, 2014). But to what end? Characteristics such as therapeutic relationship and relational practice are thought to be key features of mental health nursing. Yet little focus is placed on developing methods of inquiry to practically research these foundational practices. Mental health nurses need to deeply explore what it means to be a mental health nurse and how this translates into unique nursing practice (Barker \& BuchananBarker, 2011). Greater insight and fresh perspectives may be sought to find purpose and greater understanding of mental health nursing practice by using a method of inquiry that allows for deep critical reflection, particularly from a reflexive perspective.

Originally developed by education researchers, duoethnography is well suited to mental health nursing research because it utilizes a social justice and dialogical approach (Norris et al., 2012). Dialogue enables the researchers to uncover, increase understanding of, and become emancipated from the, "hidden structures of the oppressive ideologies that inform their identities" (Grant \& Radcliffe, 2015, p. 816). First, I will explore the strengths of duoethnography, contextualizing them in relation to mental health nursing. Issues and strategies to overcome them will then be addressed.

\section{Strengths}

Duoethnography is a narrative-based method of inquiry. The roots of this methodology emerged from autoethnography, in which a single researcher reflects on and writes about their experience (Wall, 2006). The critical difference is the engagement of more than one researcher in the challenging process of exploring meaning of a phenomenon and how it changes over time through juxtaposition of the researchers' narratives (Breault, 2016). The intention of duoethnography is not to develop two narratives of similar experience, the purpose is to critically explore the tensions between the writers who have experienced a particular phenomena to arrive at multiple understandings (Grant \& Radcliffe, 2015; Sawyer \& Norris, 2015).

Duoethnographic inquiry can be used to examine one's curriculum of living, and meaning exploration of the learning experience, rather than focusing on merely the content of day to day life (Breault, 2016). Though a relatively new method, it has been integrated into the field of curriculum development (Norris et al., 2012). Duoethnographers undergo transformative learning through examining difference in personal artifacts, stories, memories, compositions, texts and critical incidents within their own lives, and the spaces 
between self, collaborative partner, and contexts (Breckenridge \& Clark, 2017; P. Sameshima, 2013). The duoethnographic method intentionally creates transparency and articulation of perspectives, thoughts, and wonderings, purposefully creating self-reflexive reconstruction (Sameshima, 2013). The central tenets of duoethnography result in meanings created, exposed, and transformed (Sameshima, 2013), while the reader is simultaneously engaged in a dialogue with the researchers. In development of the methodology, Norris and Sawyer (2012) outlined nine elements of duoethnography: currere (understanding self), polyvocal and dialogic, disrupting metanarratives, difference between researchers, dialogic change and regenerative transformations, trustworthiness found in selfreflexivity, absence of claims in validity and truth, audience accessibility, ethical stances, and trust. Sameshima (2013) uses the term "counterpoint" to describe the composition and intentional creation of inter-textuality created when meaning is contingently generated across multiple texts where one work is reflected in another (p. 188). The value of duoethnography is in the bringing together of the complexity of the two (or more) stories of the researchers, as they overlap and interact (Breault, 2016).

There is a dearth of nursing peerreviewed research that uses duoethnographic research. Duoethnography is a well-matched method of inquiry for mental health nursing because it allows for emancipatory and transformational processes which are much needed at a time when there is increasing questioning of what it means to be a mental health nurse (Barker and Barker-Buchanan, 2011; Hurley and Ramsay, 2008; Lakeman and Molloy, 2017). Utilization of a method that engages researchers and the reader of the research in dialogue can encourage nurses to challenge the knowledge-practice gaps and dominant traditional perspectives of psychiatry, which may in turn help to overcome the limits of psychiatry and science in informing nursing practice. Contextualizing the nurse's voice and encouraging a journey of self-discovery and transformation can help mental health nurses challenge the taken for granted and silenced experiences and contexts of mental health nursing (Lakeman, 2012).

The goal of duoethnography is to highlight and uncover differences in the voices of each researcher (Sawyer and Norris, 2012). Different mental health nursing practice may be shaped by relationally situated, reflective practice that places researchers in dialogue with each other, and with the reader of the research to specifically highlight differences (Grant and Radcliffe, 2015). Engagement of the reader as an active participant in the transformative process opens possibilities of deeper and more meaningful relationships with mental health nursing research. The dissemination of duoethnographic research may give mental health nurses the opportunity to engage in reflexivity with other nurses and other health care professionals, and to reach a place of transformative learning that can help clarify what mental health nursing is and challenge current standards of best-practice. The transformative learning process may pave the way for clearer understanding of the juxtaposition between the concepts that guide the biomedical model and those that guide recovery models, and person-centred and trauma and violence informed practice (Barker \& Buchanan-Barker, 2010, 2011). Reflexivity and exploration of personal history and understanding of the phenomenon within mental health nursing promotes challenging understanding of the taken for granted. Breault (2016) discussed that certain types of researchers are drawn to the duoethnographic method, ones that enjoy thinking about their own lives and those of others. My own journey to think about the challenge of transformational learning in the duoethnogrphic process came from my own experience as a mental health nurse, an educator, and a doctoral nursing student. I saw the value in engaging in a dialogue with other researchers who have different life experiences in order to transform my own understanding of mental health nursing. The central feature that distinguishes duoethnography from autoethnography is the juxtaposition of the dialogue between the researchers that allows for reflection and opportunity for transformative 
change (Sawyer \& Norris, 2015). In challenging life experiences, the researcher challenges their own beliefs. There is value in being able to gently push boundaries to constructively challenge the existing perceptions of the other researcher (Breault, 2016). Reciprocity is built into the researcher relationship which mirrors the relationships of the nurse/patient in mental health; however, the goal is to empower each other through rigorously examined questions.

\section{Issues}

In efforts of creating a methodology that is not prescriptive, and to encourage the freedom and creativity of the researchers in the dialogue and in the presentation of it, Norris and Sawyer (2012) discussed central tenets of duoethnography as guidelines rather than a strict set of rules to be followed. However, the risk of having a free-form method is that not all researchers who attempt to engage in the duoethnographic process may end up succeeding, especially those who are accustomed to traditional research methodologies. Lack of strict procedures or steps for researchers to follow pose challenges in assessing quality and rigour of the research. How do the researchers judge whether or not they have achieved the research goal? Rigour and trustworthiness are evaluated through transparency in the transformative process (Breault, 2016). The work of Breault (2016) is drawn on heavily in this paper because, to date, it is the only peer reviewed comprehensive discussion that identifies the emerging issues in duoethnographic research and the accompanied strategies to overcome them. Beault (2016) identified the importance in achieving the nine tenets in the duoethnographic process as a means of ensuring quality through achieving meaning.

A well documented, dialectic process of revisiting and re-evaluating the central tenets of methodology are necessary to determine if the transformative process occurred.

A frequent challenge of a new method is that small research communities critique, revise, and gradually adjust the method in informal ways that are perhaps not formalized and made readily available in a detailed description of the method (Breault 2016). There is value in periodic review of the published duoethnographic research, providing critique and suggestions for improvement so that those new to the method have a guideline to follow. Breault (2016) discussed the importance of those researchers who conduct duoethnography to periodically assess the duoethnographic research that is being published in the field to see learnings and progress.

The central premise of duoethnography rests in the transformative learning process of the researchers as they engage in critical dialogue. It is more than simply two parallel autobiographies, or two parallel autoethnographies because the inquisitive questioning, the juxtaposition of the meaning making, and the telling of narrative is intended to uncover meaning of specific phenomena over time, rather than exploration of one's story or personal experience (Breault, 2016; Norris et al., 2012). It is necessary to understand how the method allows researchers to promote transformative learning of the reader. Duoethnography is an active process in which the reader of the research undertakes their own journey. The assumption of the sharing of the research is that, through reading about the transformative journey of the researchers, the reader will also engage in a transformative learning process (Sawyer and Norris, 2015). Those nurses who are drawn to duoethnography are likely to want to engage in thoughtful, engaging conversation about issues related to their practice (Breault, 2016). The goal is transformative conversation; however, the risk is that poorly executed duoethnography may result in long, perhaps interesting, but unrelated conversation, or turn into a project of selfindulgence of the researchers, rather than a place of transformative growth.

Breault (2016) described this limitation or lack of transformative change as parallel talk and theory confirmation. Parallel talk happens when stories are shared as independent monologues, rather than interactive dialogues. The phenomenon becomes apparent in the writing of the research, in which it becomes evident that the duoethongrahic process did not result in transformative change for the 
researchers; thus, the goal of the method was not achieved. Parallel talk is a trap that earlier adopters of the method frequently used, often as the result of repeatedly exploring a topic. Theory confirmation is a trap that researchers used when they approached the conversation with predetermined ideas of theory that they are seeking to confirm, test, or expand through conversation. This is often the result of the researcher using themselves as the embodiment of an established theory or research agenda. The purpose of duoethnography is to engage with a different perspective to provide the opportunity for transformative learning. Thus, the researcher must be open to having their perspectives, beliefs and understandings challenged and to the personal discomfort this may cause.

Breault (2016) conceptualizes the duoethnographic process as moving in multiple ways. In the writing of the research there must be a clear path along which the reader can see the transformative journey of the researchers. In the theory confirmation trap the researchers must understand their experiences as exemplars of that theory, moving from understanding of their individual experience to a larger cultural critique. While there may be value of simply making the critique, the greater goal of achieving transformative change is not met if the researcher adheres to their own perspective. The risk of maintaining one's perspective and missing the opportunity for transformative change is more likely to happen if both researchers share similar ideologies. Without the challenge of multiple perspectives,

transformative change is less likely to occur (Breault, 2016; Farquhar \& Fitzpatrick, 2016). A larger issue stemming from researchers sharing ideologies results when there is too much agreement or commonality between the researchers, leading to the creation of master narratives. In this trap, the conversation may reach stagnation as congruent narratives are built that do not offer the challenging or probing necessary for transformative change. Solutions include addition of another voice (inviting a third or fourth researcher), examining the literature, exploring personal artifacts, or deliberate design of probing questions for the research partner (Breault, 2016).
Breault (2016) also touched on the issue of structure with respect to the conversation. A trusting relationship is necessary between the duoethnograhpers. As with strangers, there are challenges in building trust and sitting in a place of vulnerability. Multiple questions arise in attempting to clarify the relationship. Must there be a balance in the relationship between the researchers, which ranges from complete strangers to close friends? And how is the development of the relationship navigated through the development of the research process? Similarly, if the two researchers share the same viewpoints, is there potential for growth in questioning, or does this pose the risk of existing viewpoints becoming solidified? What are standards for choosing a research partner? How can these limitations be addressed in the duoethnographic process? Arguments may be made for social distancing between researchers, in attempt to bracket out the effect of the relationship on the research. However, this may result in disconnection from the process.

Caution must be taken against the tendency for the researchers to become detached from their research (Breault, 2016; Sawyer \& Norris, 2015). The disembodiment is something that is aligned with traditional research methods that uphold objective, detached perspectives. Similarly, traditional written academic formats place value on the disembodiment of the researcher from their research. This detached presentation and interpretation is not appropriate for duoethnographic research because it reduces the probing and consideration of alternative interpretations, and the opportunity to relate to the journey through the dialogical process (Breault, 2016; Sawyer and Norris, 2015). Conventional mental health nursing research must break away from tradition to explore alternative means of presenting duoethnograhpic research, thus overcoming limitations that are deeply embedded in empirically guided research.

\section{Addressing Limitations}

If the goal of the process is a transformation, then challenging assumptions 
should be built into this process. Breault (2016) raised concerns about relying on memory for autobiographical accounts. He suggested that when researchers are attempting to actualize the goal of duoethnography - to disrupt narratives and cause transformative change - they must be willing to explore and recognize that their existing frameworks are inadequate. In challenging personal frameworks, should the researchers seek out artifacts or cultural markers to confirm or disconfirm recollections? Further, is this searching important to the process, or should this happen organically? The exploration of the perspective of the other duoethnographer can help the researcher reconceptualize the self. For example, in their duoethnography using Tanka poetry, Breckenridge and Clark (2017) highlighted the value of being able to engage in difficult and sensitive conversations, and experiencing transformative change as a result of the deep intersubjective connection they built. While biases may exist in recollection, is it necessary to challenge the accuracy of memory, or is it more important for participants to help each other explore, clarify, and find meaning? Perhaps, if the purpose is growth and transformational change, the accuracy of memory may be contingent on the issue or topic being explored.

Multiple dialogues occur simultaneously in duoethnography. The two researchers in the duoethnographic process are in dialogue with each other, and in dialogue with the reader. Duoethnography ideally results in a transformative experience for both researchers, and ultimately the reader of the research, who is also in dialogue with the research. The development of the trusting relationships between researchers is integral to the process (Breckenridge and Clark, 2017; Grant and Radcliffe, 2015; Farquar and Fitzpatrock, 2016). One of the risks for mental health nurses engaging in duoethographic research may be the lapse into using the process as a purely therapeutic tool rather than a reflexive process of inquiry. This confusion may result from the relational therapeutic practice that nurses are accustomed to in patient engagement. While critical reflection is a value process that may promote personal growth, the blurring of the boundary between co-researchers may pose ethical issues stemming from vulnerability within this relationship. To remedy this issue, Breault (2016) suggested that novice researchers establish questions and boundaries of the conversation beforehand to help maintain comfort in the conversation. For example, by discussing the level of intimacy of what is being shared and the level of probing, they may create an atmosphere of safety and trust.

\section{Knowledge Dissemination}

Dissemination of the research knowledge is the final consideration presented in my discussion. Duoethnography is an intimate, person-centred, vulnerable process. However, as with any research endeavour, the goal is to share findings with a larger audience to engage the reader of the research in a transformative process. Demonstration of quality, and opportunity to further develop the method, is only possible if clear value (quality and meaningfulness) and transparency of the research process is addressed (Breault, 2016). Transparency is achieved when the researcher allows the reader into their conversation and transformations (Breault, 2016; Pauline Sameshima, 2013). of the research that brings meaning.

While the research is not replicable, the context and learnings that the reader takes from the research can be helpful for future researchers. Readily available transcripts for the reader may be valuable, but this may pose challenges in terms of publishing the research in academic journals because of space limitations and maintaining accessibility for the reader. Breault (2016) suggested technology such as academic journals providing supplementary website links to the full transcript data. This process can provide increased transparency of the research and support learning of the reader as an active participant. However, this also requires the researchers to consider additional ethical issues, including the amount to share while still maintaining privacy. Sharing of these narratives in their entirety may be particularly sensitive in mental health nursing because of ongoing stigma. 
The Canadian Journal of Critical Nursing Discourse

See it. Speak it. Write it. Change it.

\section{Conclusion}

The purpose of this paper was to provide an exploration of duoethnography as a potential methodology to revive mental health nursing, by subverting the dominant post-positivist, scientifically driven, evidence-based practice perspective, and to gain greater understanding of mental health nursing practice. Issues that may arise from use of duoethnography methodology in mental health nursing research may emerge because of this unfamiliar and unconventional method in a nursing speciality that is facing a professional identity crisis. In the struggle to carve out a clearer identity for mental health nursing, duoethnographic methodology can encourage creative dialogue that challenges the current dominant biomedical and science-based models. The pushing of boundaries allows for integration of a narrative, arts-based approach that empowers through highlighting differences in the nursing voice, where mental health nursing can emerge as a professional leader in mental health care (Hurley \& Ramsay, 2008). Ethical permission was not required for this article because it is theoretical in nature and no research participants were involved in the production of the content.

\section{References}

Barker, P., \& Buchanan-Barker, P. (2010). The tidal model of mental health recovery and reclamation: Application in acute care settings. Issues in Mental Health Nursing. https://doi.org/10.3109/0161284090327669 6

Barker, P., \& Buchanan-Barker, P. (2011). Myth of mental health nursing and the challenge of recovery. International Journal of Mental Health Nursing, 20(5), 337-344. https://doi.org/10.1111/j.14470349.2010.00734.x

Breault, R. A. (2016). Emerging issues in duoethnography. International Journal of Qualitative Studies in Education. https://doi.org/10.1080/09518398.2016.116 2866

Breckenridge, J. P., \& Clark, M. T. (2017). Two to Tanka: poetry as a duoethnographic method for exploring sensitive topics.
Journal of Research in Nursing. https://doi.org/10.1177/1744987117720824

Farquhar, S., \& Fitzpatrick, E. (2016). Unearthing truths in duoethnographic method. Qualitative Research Journal. https://doi.org/10.1108/QRJ-07-2015-0061

Grant, A. J., \& Radcliffe, M. A. C. (2015). Resisting technical rationality in mental health nurse higher education: A duoethnography. Qualitative Report, 20(6), 815-825.

Hurley, J., Mears, A., \& Ramsay, M. (2009). Doomed to fail: The persistent search for a modernist mental health nurse identity. Nursing Philosophy, 10(1), 53-59. https://doi.org/10.1111/j.1466769X.2008.00383.x

Hurley, J., \& Ramsay, M. (2008). Mental health nursing: sleepwalking towards oblivion? Mental Health Practice. https://doi.org/10.7748/mhp2008.07.11.10. 14.c6611

Jenkins, E. K. (2014). The politics of knowledge: Implications for understanding and addressing mental health and illness. Nursing Inquiry. https://doi.org/10.1111/nin.12026

Lakeman, R. (2012). What is Good Mental Health Nursing? A Survey of Irish Nurses. Archives of Psychiatric Nursing. https://doi.org/10.1016/j.apnu.2011.10.005

Lakeman, R., \& Molloy, L. (2018). Rise of the zombie institution, the failure of mental health nursing leadership, and mental health nursing as a zombie category. International Journal of Mental Health Nursing. https://doi.org/10.1111/inm.12408

Mitchell, G. J., \& Cody, W. K. (2002). Ambiguous opportunity: Toiling for truth of nursing art and science. In Nursing Science Quarterly. https://doi.org/10.1177/0894318022210866 0

Norris, J., Sawyer, R., \& Lund, D. (2012). Duoethnography: Dialogic methods for social, health, and educational research. Alberta Journal of Educational Reesearch, 59(3), 525-528.

http://books.google.com/books?hl=en\&lr= \&id=fNswUuzGCdYC\&oi=fnd\&pg=PA5 
See it. Speak it. Write it. Change it.

$\& d q=$ Duoethnography $+:+$ Dialogic + Metho ds+for+Social,++ Health,++ and+Education $\mathrm{al}+$ Research\&ots $=7 \mathrm{SOyhAtlvq} \& \operatorname{sig}=\mathrm{xVgF}$ jDd5uP3c8MEbrgHRH4U4Jmc

Rose, P., \& Parker, D. (1994). Nursing: an integration of art and science within the experience of the practitioner. Journal of Advanced Nursing. https://doi.org/10.1046/j.13652648.1994.20061004.x

Sameshima, P. (2013). Duoethnography. Understanding qualitative research \& Duoethnography: Promoting personal and societal change within dialogic self--study. Journal of the Canadian Association for Curriculum Studies.

Sameshima, Pauline. (2013). Duoethnography.

Understanding qualitative research \&

Duoethnography: Promoting personal and societal change within dialogic self-

--study. Journal of the Canadian Association for Curriculum Studies, 11(1), 174-190.

Sawyer, R., \& Norris, J. (2015).

Duoethnography. International Review of Qualitative Research. https://doi.org/10.1525/irqr.2015.8.1.1

Wall, S. (2006). An Autoethnography on Learning About Autoethnography. International Journal of Qualitative Methods. https://doi.org/10.1177/1609406906005002 05 